\title{
Erratum: Editorial: Prophetic witness in weakness
}

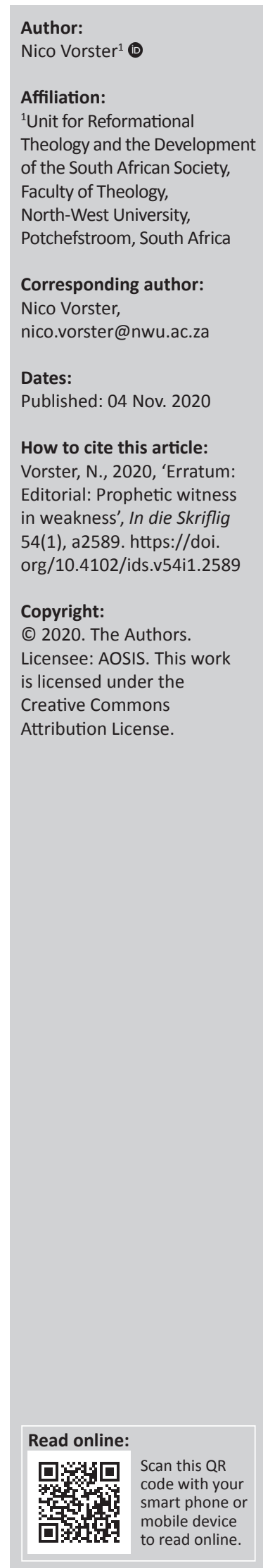

In the version of this article initially published, Vorster, N., 2019, 'Editorial: Prophetic witness in weakness', In die Skriflig 53(1), a2544. https://doi.org/10.4102/ids.v53i1.2544, the article issue number was given incorrectly. The correct issue number should be number 4 instead of number 1 .

This correction does not alter the study's findings of significance or overall interpretation of the study results. The publisher apologises for any inconvenience caused. 